\title{
Long-term, low temperature simulation of early diagenetic alterations of organic matter from conifers: Aliphatic hydrocarbons
}

\author{
SHENJUn QIN, ${ }^{1,2}$ YUZHUANG SUN ${ }^{2 *}$ and YUEGANG TANG ${ }^{1}$ \\ ${ }^{1}$ College of Resource and Safety Engineering, China University of Mining and Technology, Beijing 10008, China \\ ${ }^{2}$ Key Laboratory for Resource Exploration Research of Hebei Province, Hebei University of Engineering, Handan 056038, China
}

(Received April 26, 2009; Accepted October 9, 2009)

\begin{abstract}
Early diagenetic alterations of organic matter from conifers were simulated at low temperature of $80^{\circ} \mathrm{C}$ for five and a half years. Their diagenetic products of aliphatic hydrocarbons were identified and quantified. The results reveal that in the early sedimentation of organic matter from conifers, $n$-alkanes have developed; natural terpenoids have transformed into diagenetic terpenoids, in which some seldom reported evolutionary intermediates - two cadinatetraenes, three norabietatetraenes and one abietatetraene-were detected and identified. The diagenetic pathways for cadalane-type sesquiterpenoids and abietane-type diterpenoids are proposed. The experimental data also show that the diagenesis of aliphatic hydrocarbons is influenced by different inorganic environments. The influences can be concluded as follows: high salinity is propitious to generate and expulse aliphatic hydrocarbons; iron may promote the increase of alkanes, but interrupt the alterations of terpenoids; gypsum, when not coexisting with metal, may slow the degradation from long chain alkanes to short ones; and heavy metal probably delays the early diagenesis of both alkanes and terpenoids. These influences observed under low temperature may enrich studies on early diagenesis of organic matter from higher plants.
\end{abstract}

Keywords: coniferous organic matter, early diagenetic alternations, alphatic hydrocarbons, inorganic environment, low temperature simulation

\section{INTRODUCTION}

Early diagenesis of terrestrial organic matter from higher plants, in modern sediments, peat, lignite, etc., is one of focuses in geological research (Cranwell, 1985; Del Rio et al., 1992; Dehmer, 1995; Pancost et al., 2002; Hajje and Jaffe, 2006), in which some important discoveries about aliphatic hydrocarbons from higher plants have been reported: $n$-alkanes mainly originate from cuticle waxes and alcohols in higher plants and the dominance of long chain $n$-alkanes with odd carbon number predominance can indicate higher plant origin (Dehmer, 1995). Terpenoids are common constituents of the resins of higher plants, and they are important biomarkers for higher plants, especially for conifers. For example, the diterpenoids with skeletal structure of abietanes, pimaranes and kauranes are nonspecific markers of gymnosperm plants (Otto et al., 1997); the sesquiterpenoids with skeletal structure of the cedranes and cuparanes are specific markers of the species of the Cupressaceae (Grantham and Douglas, 1980; Otto and Wilde, 2001); and triterpenoids of oleanane, ursane and lupane classes are biomarkers for angiosperms (Otto et al., 2005). Such

\footnotetext{
*Corresponding author (e-mail: sunyz2008@hotmail.com)

Copyright $@ 2010$ by The Geochemical Society of Japan.
}

terpenoids, after undergoing complex geochemical and geological transformations, wildly exist in the geosphere and their diagenetic pathways are also the interest of some researchers. Simoneit et al. (1986) reported that retene may originate from abietic acid and abietadienes; Otto et al. (1997) suggested retene may originate from other functionalized abietane-type diterpenoids such as taxodone, dehydrosugiol and ferruginol.

The varied diagenetic pathways of terpenoids are reported to be related to diverse sedimentary environments. For instance, anoxic environments appear to be associated with formation and preservation of aromatic terpenoids (Simoneit and Mazurek, 1982). Oxygenated environments appear to be associated with hydrogenated analogues (Simoneit et al., 1986). Later investigations (Martin et al., 1999) also demonstrated that, through the anaerobic degradation by undefined microorganisms, aromatized and decarboxylated diterpenoids (such as retene) could be generated from resin acids (tricyclic diterpenoids).

However, because of the complexity of biogeochemical processes in the geosphere, investigating the origin and diagenetic pathways of organic matter from higher plants and assessing the influences of sedimentary environments on their diagenesis are difficult. Therefore, on the hypothesis that short-term heating at high temperature can result in similar changes of organic 


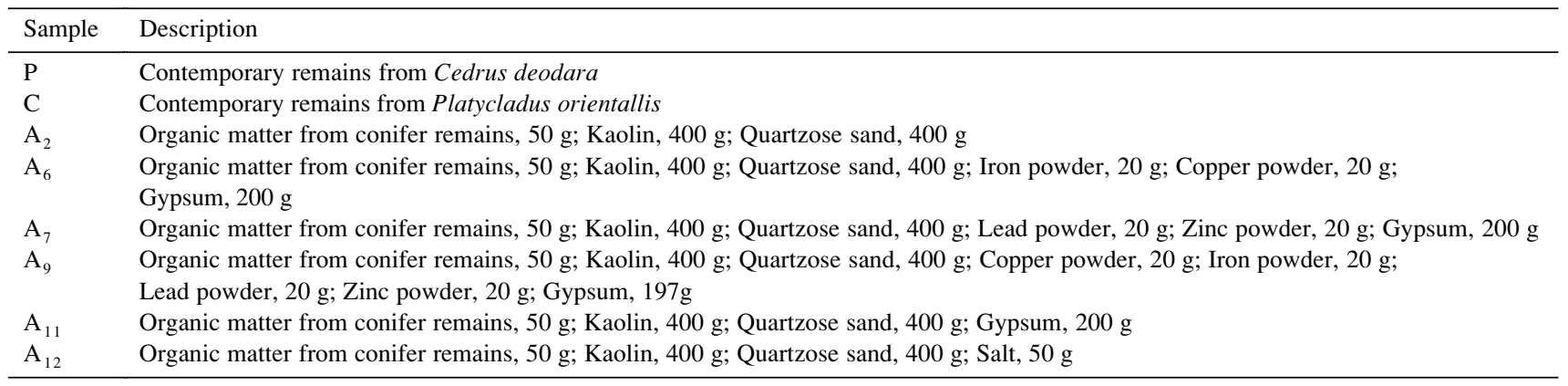

matter caused by the time-consuming geochemical evolution, thermal simulation experiments have been carried out in the laboratory to study the early generation of hydrocarbons (Shi et al., 1988, 2001; Zhang, L. Y. et al., 1999; Huo et al., 2002). But most of these experiments were conducted at high temperature $\left(200\right.$ to $\left.500^{\circ} \mathrm{C}\right)$ and for short duration (several hours to days). These experimental conditions may induce some side reactions because of an excessive supply of energy and deprive the researchers of observing the influences of biochemical and inorganic interactions on the early diagenesis of organic matter usually occurring at low temperature (Harvey et al., 1995; Zhang, Z. L. et al., 1999). So a long-term simulation experiment at low temperature $\left(80^{\circ} \mathrm{C}\right.$ at this temperature, the diagenesis of organic matter can be accelerated while most bacteria are still active) was designed.

So far, the simulated experiment has run continuously for five and a half years and some achievements have been made: The fact that immature oil can generate within a short time after sedimentation was discovered and the influences of inorganic matter such as metals $(\mathrm{Fe}, \mathrm{Pb}, \mathrm{Zn}$, $\mathrm{Cu})$, gypsum $\left(\mathrm{CaSO}_{4}\right)$ and salt $(\mathrm{NaCl})$ on the generation were discussed (Sun et al., 2006). The early generation of hydrocarbon from algae was investigated and influences of inorganic environments on it were elaborated (Qin et al., 2008). The formation of macerals of organic matter from conifers has been analyzed by microscope and conclusions that cutinite, suberinite and huminite have been formed only after one year's simulation, and that cutinite and suberinite always keep good shape and strong fluorescence in the latter simulation were drawn (Sun $e t$ al., 2008).

In the present stage of this simulation experiment, the paper tries to investigate the early diagenetic characteristics of aliphatic hydrocarbons (alkanes and terpenoids) from coniferous organic matter under different inorganic environments, which may provide valuable data and better understanding to early diagenesis of organic matter from higher plants.

\section{Materials AND Methods}

\section{Samples and sample preparation}

Leaves, branches and barks from contemporary Cedrus deodara (Pinaceae) and Platycladus orientalis (Cupressaceae) collected from the campus were grounded up and homogenized. Then these organic materials were divided into several groups and mixed with different inorganic materials respectively to keep each sample in a unique condition as shown in Table 1. After that, all samples were put into wide-mouthed bottles where a quartzose sand sheet was placed in advance and another quartzose sand sheet was added to cover the mixed materials. Then, all the contents in each bottle were submerged in purified water which was kept rising from the contents for no less than $2 \mathrm{~cm}$ (this was maintained throughout of the simulation experiment beginning from August 1, 2002). Finally, these bottles were closed and put into an oven whose temperature was controlled at $80^{\circ} \mathrm{C}$. In order to eliminate possible organic contamination, experimental materials such as bottles, containers, solid reagents and inorganic components, were pre-extracted using redistilled analytical grade solvent, and then heated at $180^{\circ} \mathrm{C}$ for 8 hours.

\section{Extraction and separation}

After the simulation continued for about five and a half years, a part of the samples were taken out from the bottles for organic geochemical analyses. The samples were Soxhlet-extracted for 36 hours using chloroform as solvent, and removal of elemental sulfur was achieved by adding copper foils to the flask during extraction. The extracts were filtered and concentrated by a rotary evaporator. The yields were determined gravimetrically after removal of the solvent. The total extract was separated into aliphatic, aromatic and polar fractions by chromatography column over pre-washed silica gel. The fractions were eluted with hexane, dichloromethane and methanol, respectively. For comparison, fresh samples collected from Cedrus deodara and Platycladus orientalis 
were washed and dried at $37^{\circ} \mathrm{C}$, and then the same extraction and separation procedures were repeated.

\section{Gas chromatography-mass spectrometry}

Gas chromatography-mass spectrometry (GC-MS) analyses of the aliphatic fractions were performed on an Agilent $6890 \mathrm{GC}$ coupled to an Agilent 5973 quadrupole MSD. Separation was achieved on a fused silica capillary column coated with DB5 $(30 \mathrm{~m} \times 0.25 \mathrm{~mm}$ i.d., 0.25 $\mu \mathrm{m}$ film thickness). The $\mathrm{GC}$ operating conditions were as follows: temperature held at $60^{\circ} \mathrm{C}$ for $5 \mathrm{~min}$, increased from 60 to $300^{\circ} \mathrm{C}$ at a rate of $4^{\circ} \mathrm{C} \mathrm{min}{ }^{-1}$ with final isothermal hold at $300^{\circ} \mathrm{C}$ for $15 \mathrm{~min}$. Helium was used as carrier gas. The sample was injected at split ratio 30:1 with the injector temperature at $290^{\circ} \mathrm{C}$. The mass spectrometer was operated in the electron impact mode at $70 \mathrm{eV}$ ionization energy and scanned from 50 to 650 Da. Data were acquired and processed with the Chemstation software. Individual compounds were identified by comparison of mass spectra with literature and library data, and by interpretation of mass spectrometric fragmentation patterns.

\section{RESULTS AND DISCUSSION}

\section{Composition of the aliphatic fractions}

The low evolutionary degree of organic matter leads to a relative high concentration of polar compounds (34.70-56.58\%) but a low concentration of aliphatic $(1.47-15.29 \%)$ and aromatic $(1.58-10.51 \%)$ fractions in the total extracts. From Table 2, it can be seen that the composition of extracts is different in different sample conditions. In samples $\mathrm{A}_{6}, \mathrm{~A}_{9}$ and $\mathrm{A}_{12}$, the concentrations of aliphatic hydrocarbons are higher than that in sample $\mathrm{A}_{2}$ where only organic matter, kaolin and quartzose sand exist. The increased amount of aliphatic hydrocarbons in sample $A_{6}$ and $A_{9}$ may come from the generation of alkanes from polar compounds under the catalysis of iron or its compounds. For example, iron sulphide in samples can catalyze decarboxylation of fatty acids to produce alkanes (Zhang, Z. L. et al., 1999). The increased amount of aliphatic hydrocarbons (alkanes and terpenoids) in sample $A_{12}$ may result from the high briny environment, in which generation and expulsion of aliphatic hydrocarbons can be accelerated. This is consistent with the fact that salt lake facies and brackish water facies are favorable to form immature oils (Huang, 1999). In samples $A_{7}$ and $\mathrm{A}_{11}$, the concentrations of aliphatic hydrocarbons are lower than that in sample $A_{2}$. This may be brought about by prohibitive effect of the heavy metal (lead) and the gypsum, which will be supported in the latter part of this paper.

The total ion chromatograms (TIC) show that the composition of aliphatics is also different in different sample

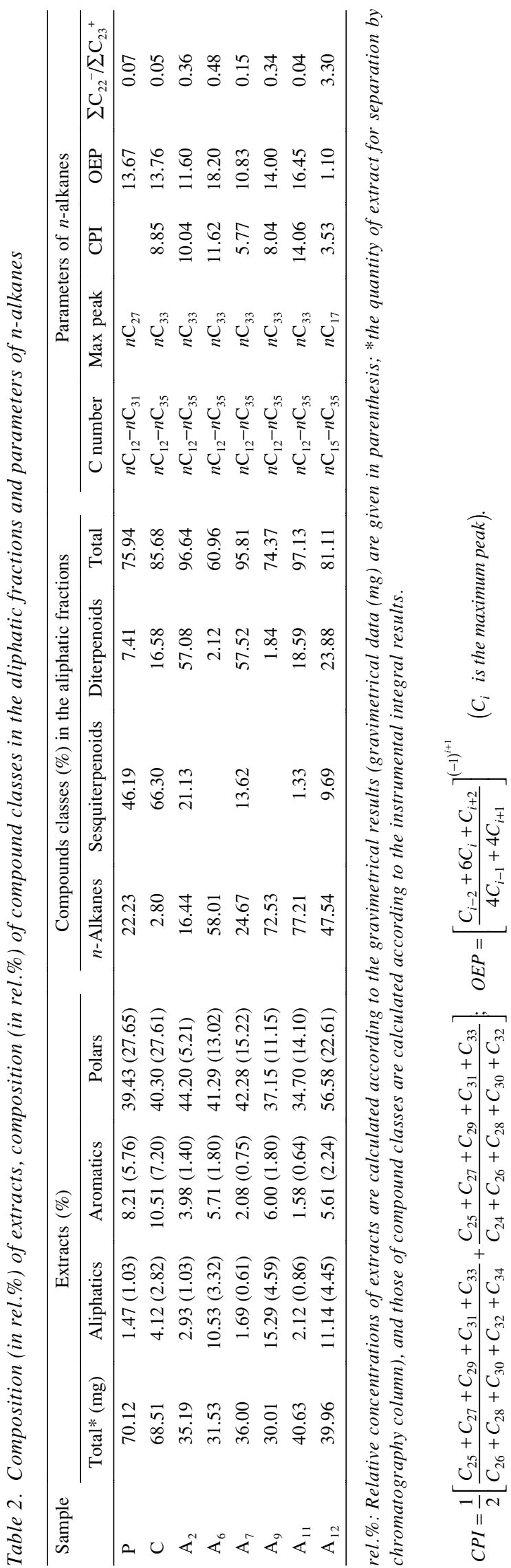

Simulation of early diagenetic alterations of organic matter from conifers 

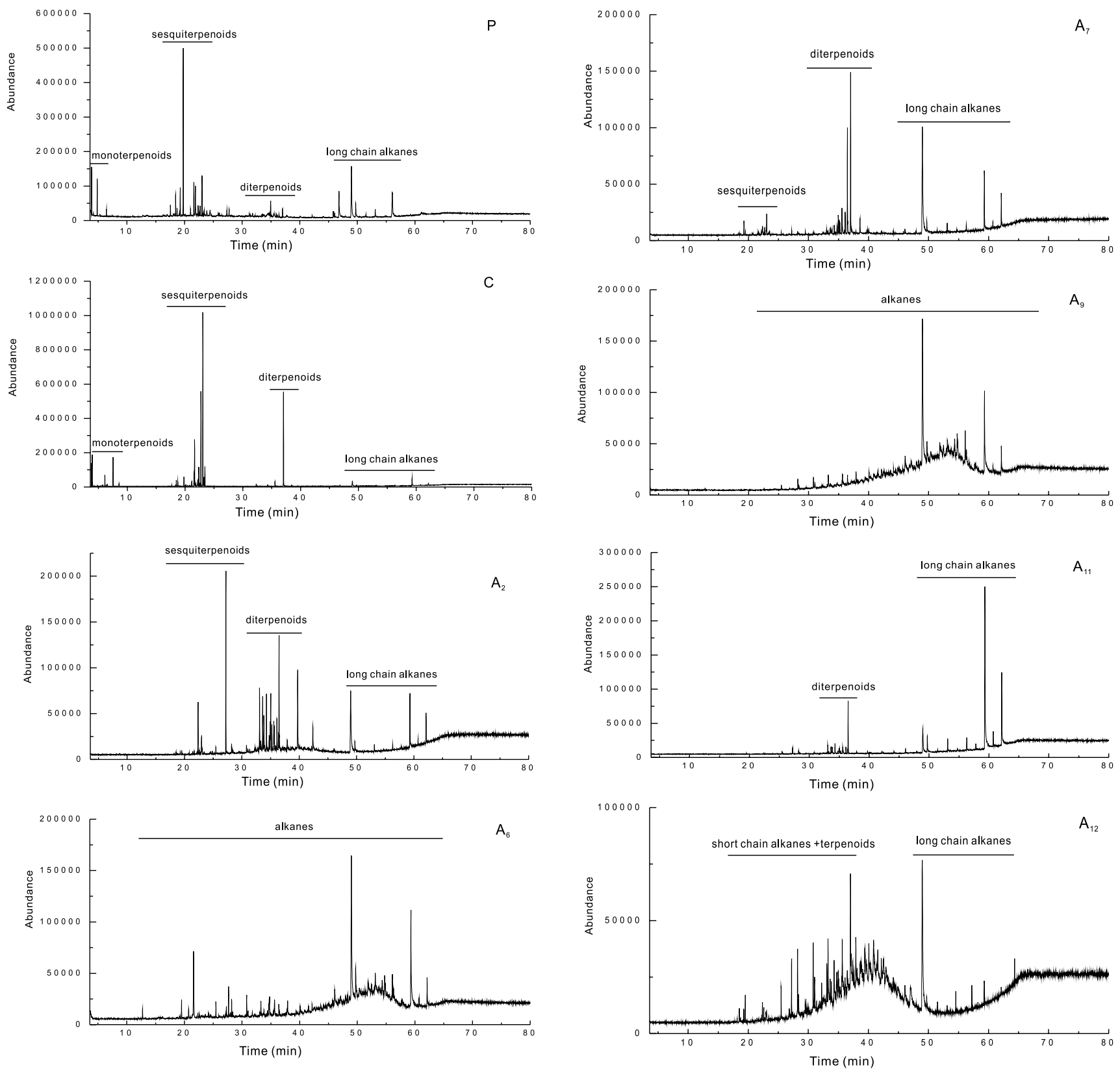

Fig. 1. GC-MS (TIC) traces of the aliphatic fractions of samples.

conditions (Fig. 1 and Table 2). In contemporary samples $\mathrm{P}, \mathrm{C}$ and simulated samples $\mathrm{A}_{2}, \mathrm{~A}_{7}$, the amount of sesquiand diterpenoids dominates the aliphatic fractions; alkanes are minor components. In samples $\mathrm{A}_{11}$ and $\mathrm{A}_{12}$, the amount of alkanes ranks first among aliphatic fractions; the amount of terpenoids comes afterward. However, in samples $A_{6}$ and $A_{9}$ into which iron powder was added, terpenoids seem to be "used up", so the amount of alkanes occupies a leading position. The causes of these distinct compositional characteristics will be discussed later.

\section{$N$-alkane distribution}

According to the mass chromatograms $(\mathrm{m} / \mathrm{z} 85 \mathrm{key}$ ion for alkanes) of $n$-alkanes (Fig. 2), long chain $n$-alkanes are dominant components in the contemporary samples $\mathrm{P}$ and $\mathrm{C}$, which displays the characteristic of higher plant sources (Dehmer, 1995). In sample $\mathrm{P}, \mathrm{C}_{27}$ is the main peak of mass chromatogram; in sample $\mathrm{C}, \mathrm{C}_{33}$ is the main peak. The difference of main peak between two samples is mainly caused by their different biological composition of cuticle waxes and alcohols. 

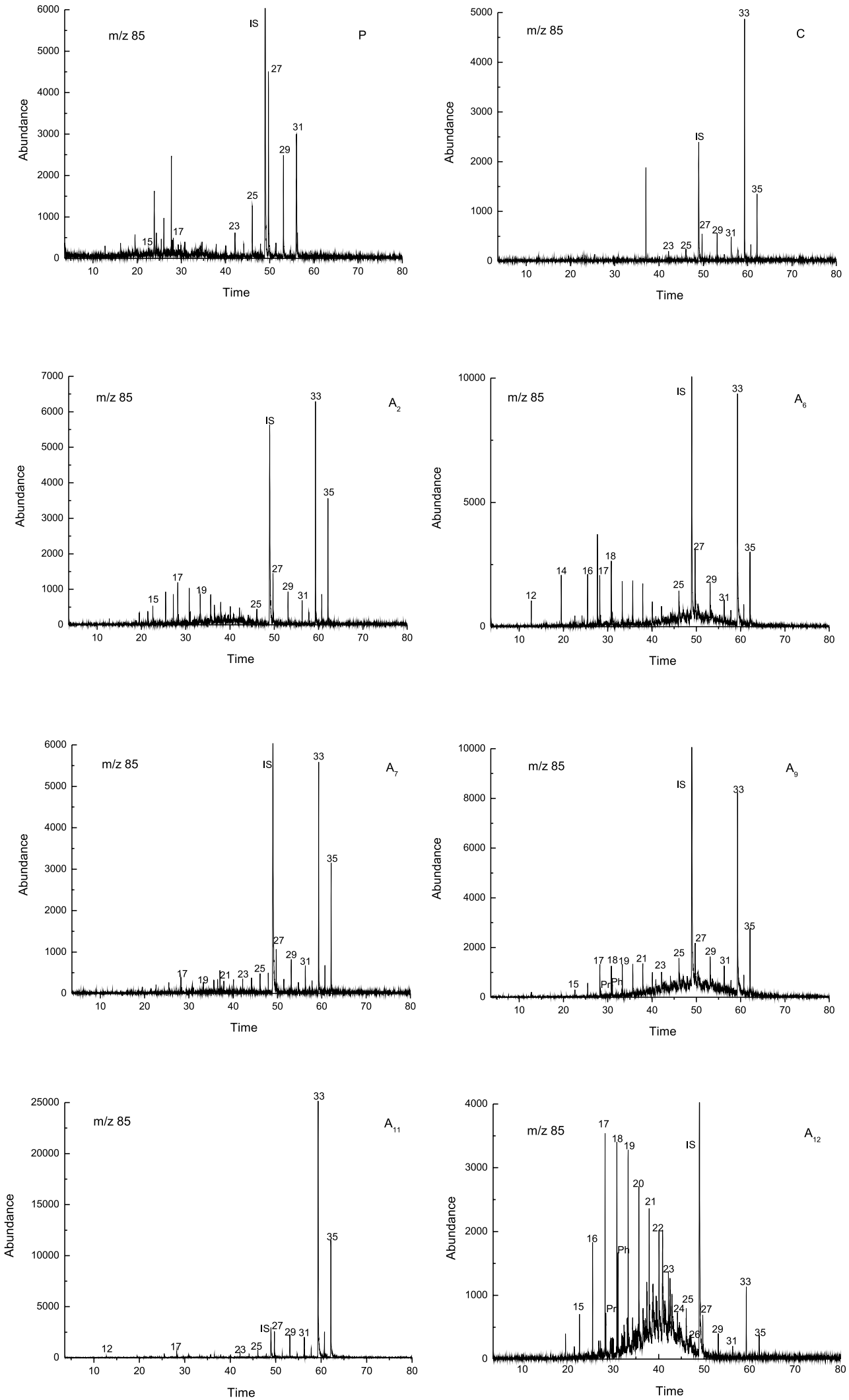

Fig. 2. Mass chromatograms $(\mathrm{m} / \mathrm{z} 85)$ of $n$-alkanes of samples. $\mathrm{Pr}=$ pristine, $P h=$ phytane, IS $=$ the internal standard $($ squalane $)$.

Simulation of early diagenetic alterations of organic matter from conifers

251 


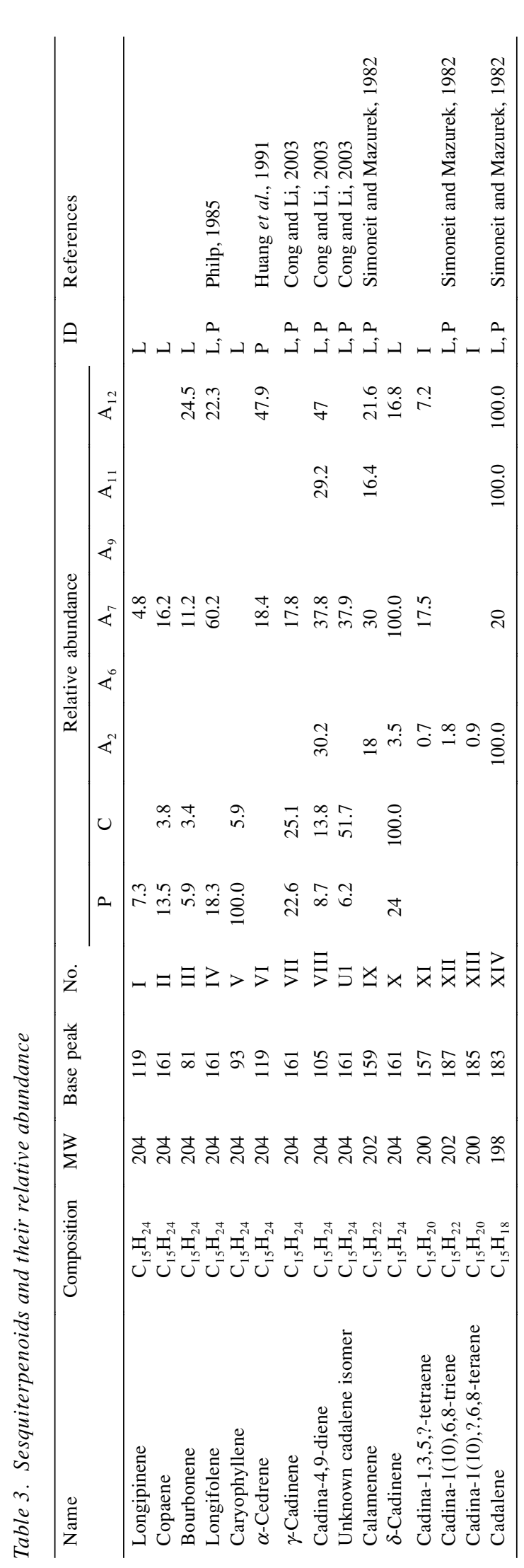

In all simulated samples excluding $\mathrm{A}_{12}, \mathrm{C}_{33}$ is the main peak of mass chromatogram and long chain $n$-alkanes still dominate components. In samples $\mathrm{A}_{2}, \mathrm{~A}_{6}$ and $\mathrm{A}_{9}$, the percentage of long chain $n$-alkanes is far beyond that of short chain $n$-alkanes, and the values of $\Sigma \mathrm{C}_{22}{ }^{-} / \Sigma \mathrm{C}_{23}{ }^{+}$are 0.36 , 0.48 and 0.34 respectively (Table 3 ). However, compared with contemporary samples, the short chain $n$-alkanes in these samples have increased. In sample $A_{12}$, where $C_{17}$ is the main peak of mass chromatogram, increase of short chain $n$-alkanes is significant and it even surpasses long chain $n$-alkanes $\left(\sum \mathrm{C}_{22}{ }^{-} / \Sigma \mathrm{C}_{23}{ }^{+}=3.30\right)$. The obvious increase of short chain $n$-alkanes shows that during the longterm simulation, thermo-chemical processes promote the maturity of short chain $n$-alkanes, in which bacteria may play an important role. According to Otto et al. (1994) and Dehmer (1995), microbial activity could contribute to the increase of $n$-alkanes shorter than $n$-C23 from higher plants. The role of bacteria is also suggested by the hump in the TIC curve of every above-mentioned sample (Fig. 1, Peters and Moldowan, 1993). In sample $A_{12}$, the plot distribution of TIC curve with an obvious hump tends to become smooth, and the value of odd over even carbon preference (OEP) and carbon preference index (CPI) is close to 1 . This shows that bacteria remarkably reduced odd carbon preference of $n$-alkanes from organic matter through their degradation during early diagenesis at $80^{\circ} \mathrm{C}$ (Zhang, 1979). Since sample $\mathrm{A}_{12}$ is kept in a hypersaline condition, it should be halophilic bacteria that assisted the generation and maturity of alkanes in hypersaline environment.

In sample $\mathrm{A}_{7}$, however, the increase of short chain $n$ alkanes is not obvious. The percentage of its long chain $n$-alkanes in the aliphatic surpasses that in sample $\mathrm{A}_{12}$, $\mathrm{A}_{2}, \mathrm{~A}_{6}$, and $\mathrm{A}_{9}$. This percentage reaches the highest point in sample $\mathrm{A}_{11}$, whose $\sum \mathrm{C}_{22}{ }^{-} / \Sigma \mathrm{C}_{23}{ }^{+}$is 0.04 . This may be caused by the interference of gypsum with biochemical degradation of bacteria. According to Peters and Moldowan (1993), biochemical degradation occurs preferentially from alkanes under the temperature from 65 to $80^{\circ} \mathrm{C}$. This process must be isolated from hydrogen sulphide $\left(\mathrm{H}_{2} \mathrm{~S}\right)$ because of its toxicity to associated bacteria. However, in early sedimentation of organic matter, when the temperature is below from 80 to $100^{\circ} \mathrm{C}$, this biochemical degradation may be hampered by commonly-happened bacterial sulphate reduction (BSR), in which sulphate is the source of $\mathrm{H}_{2} \mathrm{~S}$ generation (Disnar and Sureau, 1990; Machel et al., 2001). Therefore, in sample $\mathrm{A}_{11}$, where gypsum $\left(\mathrm{CaSO}_{4}\right)$ was added and metals did not exist, gypsum may be reduced to $\mathrm{H}_{2} \mathrm{~S}$. It may poison the associated bacteria and hamper the development of short chain alkanes from long chain alkanes. But in other samples $\left(\mathrm{A}_{6}, \mathrm{~A}_{7}, \mathrm{~A}_{9}\right)$ into which gypsum was also added but metals existed, the degradation of the bacteria was less interfered with. It is probably because the hydrogen sulphide 
has firstly combined with free metals to form metallic sulphides.

\section{Sesquiterpenoids}

In this simulation experiment, the sesquiterpenoids and diterpenoids in the aliphatic fractions, observed from GCMS data, are mainly unsaturated and aromatic. According to related research, aromatic hydrocarbons of low molecular weight and aromatic terpenoids can appear in aliphatic (saturated) fractions (Stefanova et al., 2005).

In contemporary samples, natural sesquiterpenoids dominate the aliphatic fractions (Fig. 1 and Table 4) where caryophyllene $(\mathrm{V})$ is the maximum component of sample $\mathrm{P}$ and $\delta$-cadinene $(\mathrm{X})$ of sample $\mathrm{C}$. However, in simulated samples, most natural sesquiterpenoids evolved into diagenetic sesquiterpenoids through thermal-chemical and biochemical processes. In samples $\mathrm{A}_{2}, \mathrm{~A}_{11}$ and $\mathrm{A}_{12}$, some natural sesquiterpenoids disappeared, but some diagenetic cadalane-type sesquiterpenoids often reported in the geosphere were found. For example, evolutionary intermediates calamenene (IX) and cadina-1(10),6,8-triene (5,6,7,8-tetrahydrocadalene, XII), and evolutionary final product cadalene (XIV) (Simoneit and Mazurek, 1982; Otto et al., 1997), whose relative concentration was the highest of above samples, had been detected from the samples. It shows that the cadalane-type biogenic precursors can evolve rapidly during early diagenesis.

In addition, through the study of diagenesis of sesquiterpenoids, two kinds of seldom reported intermediates from cadinatriene to cadalene in sample $A_{2}$ were inferred according to their mass fragments (Fig. 3). They were tentatively identified as cadina-1,3,5,?-tetraene (XI) and cadina-1(10),?,6,8-tetraene (XIII). The former type was once reported as analogs in the deep oil from Bella Coola (Simoneit et al., 1986), but their mass spectra were not provided. Based on this, a complementary scheme for early diagenesis of cadalane-type biogenic precursors (cadinenes and cadinols) is proposed (Fig. 4A).

In sample $A_{7}$, most of the natural sesquiterpenoids exist and $\delta$-cadinene is still the main component. The relative concentration of cadalene in detected diagenetic sesquiterpenoids is only $20.0 \%$. This indicates that the diagenesis of sesquiterpenoids in this sample is relatively slow. The reason may be that the heavy metal (lead) hindered the biochemical conversion of sesquiterpenoids through poisoning the involved bacteria (the bacterial role in the alterations of terpenoids can refer to the next section of diterpenoids).

In samples $A_{6}$ and $A_{9}$, no obvious natural and diagenetic sesquiterpenoids were found. This may be caused by the chemical reactions of the iron added in the samples. Theoretically, iron or its uncertain complexes under the simulated conditions may coordinate with the polar precursors or catalyze the polymerization or oxy-

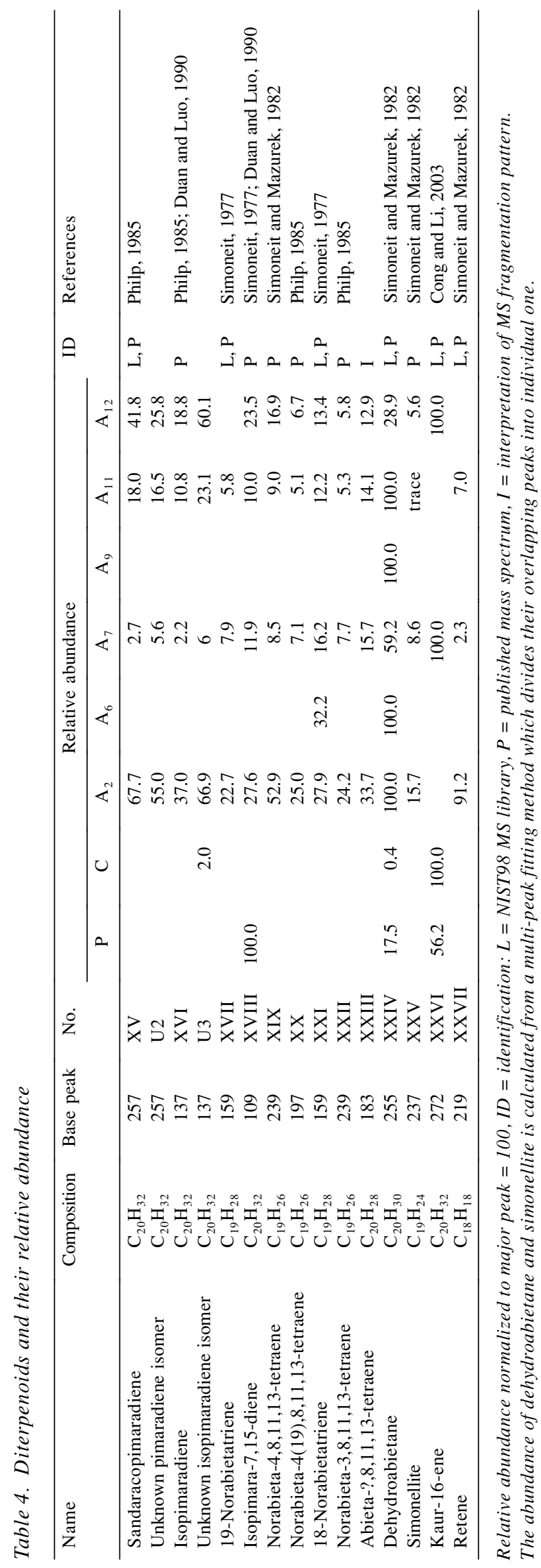

Simulation of early diagenetic alterations of organic matter from conifers 

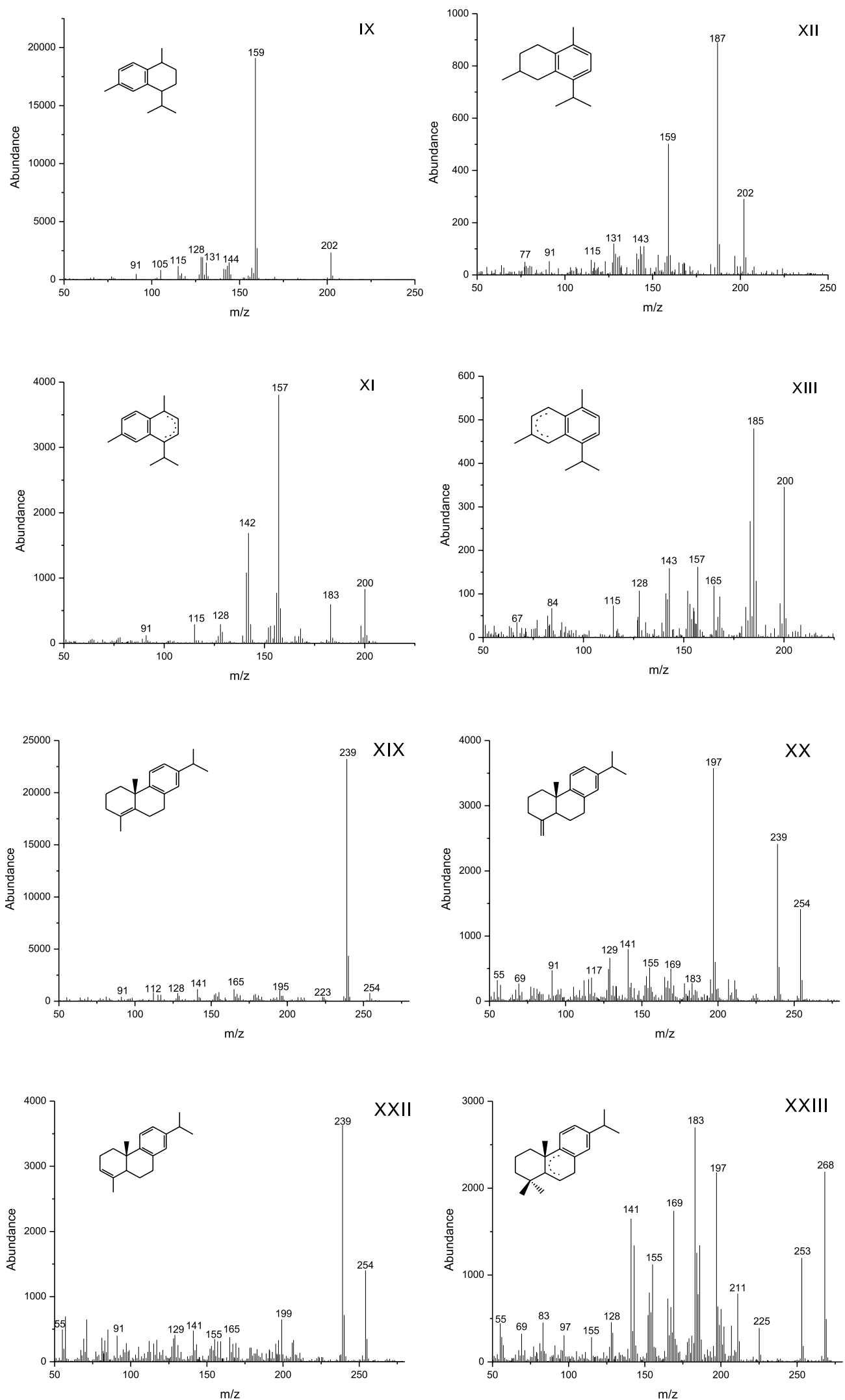

Fig. 3. Mass spectra of cadinatrienes, cadinatetraenes, norabietatetraenes and abietatetraene. IX calamenene, XI cadina-1,3,5,?tetraene, XII cadina-1(10),6,8-triene, XIII cadina-1(10),?,6,8-teraene, XIX norabieta-4,8,11,13-tetraene, XX norabieta4(19),8,11,13-tetraene, XXII norabieta-3,8,11,13-tetraene, XXIII abieta-?,8,11,13-tetraene. 

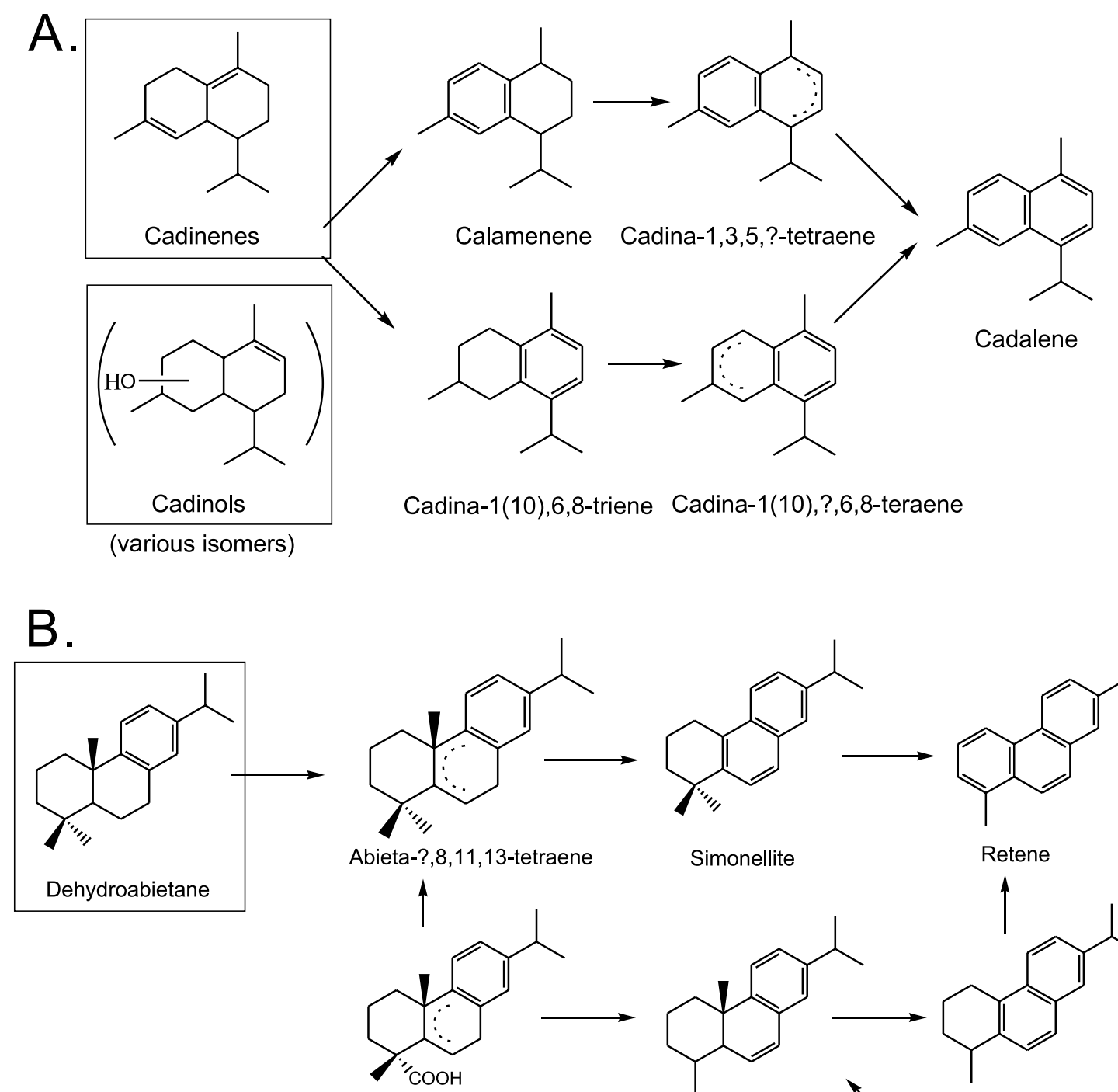<smiles>Cc1cccc2c1ccc1cc(C(C)C)ccc12</smiles>

Abieta-?,8,11,13-tetraenoic acid Norabietatetraene

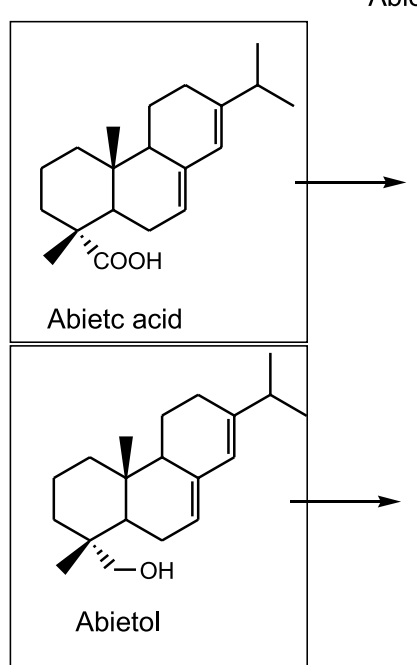<smiles>CC(C)c1ccc2c(c1)CCC1[C@@](C)(C(=O)O)CCC[C@@]21C</smiles>
(isomers)

Simonellite<smiles>[R][Ca]</smiles><smiles>CC(C)c1ccc2c(c1)C=CC1C(C)CCC[C@]1(C)c1cc(C(C)C)ccc1-2</smiles>

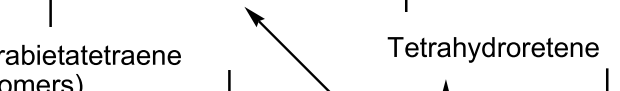
dehydroabietic acid<smiles>CC(C)c1ccc2c(c1)CCC1[C@@](C)(CO)CCC[C@]21C</smiles>

dehydroabietol

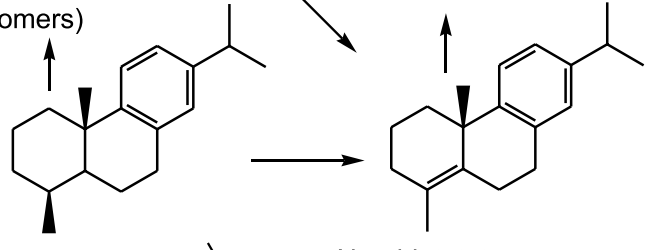<smiles>C=C1CCC[C@]2(C)c3ccc(C(C)C)cc3CCC12</smiles>

Norabieta-4(19),8,11,13-tetraene

Fig. 4. Proposed early diagenetic pathways for cadalane-type biogenic precursors (A) and abietane-type biogenic precursors (B). Compounds in boxes are biogenic precursors. (after Simoneit and Mazurek, 1982; Simoneit et al., 1986; Otto and Simoneit, 2001). 
genation of cadinenes (Britovsek et al., 2002; Bruijnincx et al., 2008), which may distort the diagenetic pathways of sesquiterpenoids.

In brief, all the results indicate that during early diagenesis, natural sesquiterpenoids can evolve into geological ones rapidly, and this process seems to be influenced by inorganic environments.

\section{Diterpenoids}

From Fig. 1 and Table 4, it can be seen that in contemporary samples $\mathrm{P}$ and $\mathrm{C}$, only a few biogenic diterpenoids in the aliphatic fractions were detected. However, in simulated samples $\mathrm{A}_{2}, \mathrm{~A}_{7}$ and $\mathrm{A}_{12}$, besides biogenic diterpenoids, many diagenetic tricyclic diterpenoid derivatives such as evolutionary intermediates norabietatrienes (XVII and XXI) and simonellite (XXV), and evolutionary final product retene (XXVII) frequently reported in the geosphere (Simoneit, 1977; Otto and Simoneit, 2001) were also found. In addition, two kinds of less frequently reported diterpenoid intermediates were identified through their mass spectra (Fig. 3). They are norabietatetraenes (XIX, Simoneit and Mazurek, 1982; XX and XXII, Philp, 1985) and abietatetraene (XXIII).

Based on data of these detected diterpenoids (Table 4) and relevant reports (Simoneit and Mazurek, 1982; Simoneit et al., 1986; Otto and Simoneit, 2001), an early evolutionary pathway for abietane-type biogenic precursors (dehydroabietane, abietic acid and abietol) is proposed (Fig. 4B), and some new conversions such as the generation of two norabietatetraenes through elimination reaction from dehydroabietol are suggested.

All of these findings show that diterpenoids in simulated samples have evolved in their early diagenesis. The evolutionary speed of diterpenoids in sample $A_{2}$ is the fastest of all and its relative abundance of evolutionary final product retene reaches $91.2 \%$ (Table 4). The maximum peak of diterpenoids in sample $A_{11}$ is the same as sample $A_{2}$, but its relative abundance of evolutionary products is much lower than that in sample $A_{2}$ and simonellite in sample $A_{11}$ is only detected in trace, which may result from the negative role that gypsum played in the evolution of diterpenoids as it did in that of $n$-alkanes. In samples $A_{6}$ and $A_{9}$, only a few tricyclic diterpenoids were detected. The lack of diterpenoids, like the case for sesquiterpenoids, may also come from the reactions of iron with the polar precursors such as abietic acids and pimarenoic acids.

Although evolution of diterpenoids is different in different samples, their biogenetic precursors, observed from the scheme in Fig. 4B, mainly converted into aromatic derivatives. According to a simulation at $550^{\circ} \mathrm{C}$ (Dai and Mei, 1988), aromatic diterpenoids, together with minor saturated diterpenoids, could be transformed from biogenetic precursors abietic acid by thermal process. Aro- matic derivatives could also form through biomass burning (Simoneit et al., 2000). This shows that alterations of terpenoids from conifers can be accelerated by thermalchemical processes, in which biogenetic neutral terpenoids (e.g., dehydroabietane) and functional terpenoids (e.g., abietic acid, phenol and pimarenoic acid), may undergo complicated reactions such as isomerization, dehydrogenation, aromatization, dealkylation and defunctionalization in the long-term simulation experiment.

Whereas, it should be pointed out that some saturated cyclic sesqui-and diterpenoids frequently reported in the geosphere, such as cadinane, abietane, fichtelite, pimarane, and norpimarane, were not encountered in all samples. These saturated terpenoids are regarded as products of reductive diagenesis or disproportionation from their precursors, which are mainly bonded to macromolecular organic fraction (i.e., kerogen), so they are often observed in more mature samples (e.g., petroleum and coal) and more oxygenated environments. However, dehydrogenated and aromatic terpenoids are mainly presented and preserved in recent sediments and anoxic conditions (Simoneit et al., 1986; Dehmer, 1995). Therefore, in the simulated samples, the absence of saturated cyclic terpenoids may likely result from the low maturity of organic matter and the dominance of an anoxic environment, where dehydrogenated and aromatic terpenoids can be easily transformed and preserved through microbial activities (Martin et al., 1999).

In a summary, like sesquiterpenoids, natural terpenoids can transform into diagenetic terpenoids in their early diagenesis rapidly, and this process can be affected by thermal-chemical processes and microbial activities.

\section{SUMMARY AND CONCLUSIONS}

The results of the simulation show that the aliphatic hydrocarbons of coniferous organic matter can undergo rapid diagenetic alterations after early sedimentation. After five and a half years of long-term, low-temperature simulation, $n$-alkanes developed and some terpenoid biomarkers, including frequently encountered ones in the geosphere (e.g., cadalene, retene and simonellite) and seldom-reported ones (two cadinatetraenes, three norabietatetraenes and one abietatetraene) in the literature, were detected in most simulated samples. Based on these findings, two complementary pathways of early diagenesis for cadalane-type sesquiterpenoids and for abietane-type diterpenoids are proposed.

Studies on early diagenesis of organic matter from conifers also reveal that the alterations of aliphatic hydrocarbons could be accelerated by thermal-chemical processes, in which bacteria play an important role. Bacteria degraded long chain $n$-alkanes into short chain $n$ - 
alkanes, which reduces the odd over even carbon number preference of $n$-alkanes, and promoted the formation of aromatic sesquiterpenoids and diterpenoids. The alterations could also be influenced by inorganic sedimentary environments. According to the experimental results, the following conclusions can be drawn: briny environment is propitious to the early generation, maturation and expulsion of aliphatic hydrocarbons; iron, through its inorganic interactions, may promote the development of alkanes, but interrupt the alternations of terpenoids; heavy metal and gypsum, through the toxicity or hindrance to associated bacteria, may hamper the early diagenesis of aliphatic hydrocarbons.

Acknowledgments-We thank Prof. Ken Sawada, two anonymous reviewers and the editor for their helpful comments. We gratefully acknowledge financial support for this study by the National Natural Science Foundation of China (NSFC, No. 40773040) and the National Basic Research Program of China (NBRPC, No. 2003CB214607).

\section{REFERENCES}

Britovsek, G. J. P., Cohen, S. A., Gibson, V. C., Maddox, P. J. and Van Meurs, M. (2002) Iron-catalyzed polyethylene chain growth on zinc: linear-olefins with a Poisson Distribution. Angew. Chem. Int. Ed. 41, 489-491.

Bruijnincx, P. C. A., Buurmans, I. L. C., Gosiewska, S., Moelands, M. A. H., Lutz, M., Spek, A. L., van Koten, G. and Klein Gebbink, R. J. M. (2008) Iron(II) complexes with bio-inspired N,N,O ligands as oxidation catalysts: Olefin epoxidation and cis-dihydroxylation. Chem. Eur. J. 14, 1228-1237.

Cong, P. Z. and Li, S. Y. (2003) Mass Spectrometry of Natural Products. Chinese Medicine and Technology Publishing House, Beijing, 1478 pp. (in Chinese).

Cranwell, P. A. (1985) Long chain unsaturated ketones in recent lacustrine sediments. Geochim. Cosmochim. Acta 49, 1545-1551.

Dai, Q. L. and Mei, B. W. (1988) Diagenetic products and thermo-transformation of resinous diterpenoids. Oil\&Gas Geology 9, 115-124 (in Chinese with English abstract).

Dehmer, J. (1995) Petrological and organic geochemical investigation of recent peats with known environments of deposition. Int. J. Coal Geol. 28, 111-138.

Del Rio, J. C., Gonzalez-vila, F. J. and Martin, F. (1992) Variation in the content and distribution of biomarkers in two closely situated peat and lignite deposits. Org. Geochem. 18, 67-78.

Disnar, J. R. and Sureau, J. F. (1990) Organic matter in ore genesis: Progress and perspectives. Org. Geochem. 16, 577599.

Duan, Y. and Luo, B. J. (1990) Distributional and evolutionary characteristics of the tri- and tetracyclic diterpenoids in modern marsh sediments. Acta Sedimentologica Sinica 8 , 114-119 (in Chinese with English abstract).

Grantham, P. J. and Douglas, A. G. (1980) The nature andorigin of sesquiterpenoids in some Tertiary fossil resins. Geochim. Cosmochim. Acta 44, 1801-1810.

Hajje, N. and Jaffe, R. (2006) Molecular characterization of Cladium peat from the Florida Everglades: biomarker associations with humic fractions. Hydrobiologia 569, 99112.

Harvey, H. R., Tuttle, J. H. and Bell, J. T. (1995) Kinetics of phytoplankton decay during simulated sedimentation: Changes in biochemical composition and microbial activity under oxic and anoxic conditions. Geochim. Cosmochim. Acta 59, 3367-3377.

Huang, D. F. (1999) Advances in hydrocarbon generation theory (I) Generation and evolution model for immature oils and hydrocarbon. J. Petrol. Sci. Eng. 22, 121-130.

Huang, Y. S., Fu, J. M., Sheng, G. Y. and Zhao, B. Q. (1991) Identification and confirmation of Cuparene in high wax oils and source rocks. Geochimica 3, 176-182 (in Chinese with English abstract).

Huo, Q. L., Feng, Z. H. and Fu, L. (2002) Hydrocarbon generation of nonhydrocarbon and asphaltene in thermal simulated experiment. Geology-Geochemistry 30, 64-67 (in Chinese with English abstract).

Machel, H. G., Krouse, H. R. and Sassen, R. (2001) Bacterial and thermochemical sulfate reduction in diagenetic Settingsold and new insights. Sediment. Geol. 140, 143-175.

Martin, J. J. V., Yu, Z. T. and Mohn, W. W. (1999) Recent advances in understanding resin acid biodegradation: microbial diversity and metabolism. Arch. Microbiol. 172, 131138 .

Otto, A. and Simoneit, B. R. T. (2001) Chemosystematics and diagenesis of terpenoids in fossil conifer species and sediment from the Eocene Zeitz formation, Saxony, Germany. Geochim. Cosmochim. Acta 65, 3505-3527.

Otto, A. and Wilde, V. (2001) Sesqui-, di- and triterpenoids as chemosystematic markers in recent conifers: A review. Bot. Rev. 67, 141-238.

Otto, A., Walther, H. and Puttmann, W. (1994) Molecular composition of a leaf-bearing and root-bearing Oligocene Oxbow Lake Clay in the Weisselster Basin, Germany. Org. Geochem. 22, 275-286.

Otto, A., Walther, H. and Puttmann, W. (1997) Sesqui- and diterpenoid biomarkers preserved in Taxodum-rich Oligocene oxbow lake clays, Weisselster basin, Germany. Org. Geochem. 26, 105-115.

Otto, A., Simoneit, B. R. T. and Rember, W. C. (2005) Conifer and angiosperm biomarkers in clay sediments and fossil plants from the Miocene Clarkia Formation, Idaho, USA. Org. Geochem. 36, 907-922.

Pancost, R. D., Baas, M., van Geel, B. and Sinninghe Damste, J. S. (2002) Biomarkers as proxies for plant inputs to peats: an example from a sub-boreal ombrotrophic bog. Org. Geochem. 33, 675-690.

Peters, K. E. and Moldwan, J. M. (1993) The Biomarker GuideInterpreting Molecular Fossils in Petroleum and Ancient Sediments. Prentice Hall, Englewood Cliffs, New Jersey, 363 pp.

Philp, R. P. (1985) Fossil Fuel Biomarkers: Applications and Spectra (Methods in Geochemistry and Geophysik). Elsevier, Amsterdam, 294 pp. 
Qin, S. J., Sun, Y. Z. and Tang, Y. G. (2008) Early hydrocarbon generation of algae and influences of inorganic environments during low temperature simulation. Energ. Explor. Exploit. 26, 377-396.

Shi, J. Y., Wang, B. S., Zhang, L. J. and Hong, Z. Q. (1988) Study on diagenesis of organic matter in immature rocks. Org. Geochem. 13, 869-874.

Shi, J. Y., Xing, M. J. and Qu, D. C. (2001) Thermal simulation experiment and evolution of fatty acid in immature oil source rocks. Chin. Sci. Bull. 46, 1567-1572 (in Chinese with English abstract).

Simoneit, B. R. T. (1977) Diterpenoid compounds and other lipids in deep-sea sediments and their geochemical significance. Geochim. Cosmochim. Acta 41, 473-476.

Simoneit, B. R. T. and Mazurek, M. A. (1982) Organic matter of the troposphere-II. Natural background of biogenic lipid matter in aerosols over the rural western United States. Atmos. Environ. 16, 2139-2159.

Simoneit, B. R. T., Grimalt, J. O., Wang, T. G., Cox, R. E., Hatcher, P. G. and Nissenbaum, A. (1986) Cyclic terpenoids of contemporary resinous plant detritus and of fossil woods, ambers and coals. Org. Geochem 10, 877-889.

Simoneit, B. R. T., Rogge, W. F., Lang, Q. and Jaffé, R. (2000) Molecular characterization of smoke from campfire burning of pine wood (pinus elliottii). Chemosphere - Global Change Science 2, 107-122.
Stefanova, M., Markova, K., Marinov, S. and Simoneit, B. R. T. (2005) Molecular indicators for coal-forming vegetation of the Miocene Chukurovo lignite, Bulgaria. Fuel 84, 18301838 .

Sun, Y. Z., Lu, J. L., Chen, J. P., Li, P., Jin, K. K. and Wang, P. (2006) Experimental study of decay conditions of organic matter and its significant for immature oil generation. Energ. Explor. Exploit. 24, 161-170.

Sun, Y. Z., Qin, S. J., Wang, P., Jin, K. K. and Lu, J. L. (2008) Experimental study of earlier formation processes of macerals. World Journal of Engineering 5, 101-102.

Zhang, L. Y., Zhang, S. C., Huang, K. Q., Zhuo, Q. G., Hong, Z. H., Huang, D. F. and Wang, T. G. (1999) Simulation experiment of immature oil genetic mechanism in lake facies of semi-salt. Chin. Sci. Bull. 44, 980-988.

Zhang, Y. G. (1979) The origin of petroleum and microbes. Petroleum Geology and Experiment 1, 53-63 (in Chinese with English abstract).

Zhang, Z. L., Sun, Y. H., Lao, Y. X. and Lin, W. Z. (1999) Catalytic decarboxylation of fatty acid by iron-containing minerals in immature oil source rocks at low temperature. Chin. Sci. Bull. 44, 1523-1526.

\section{APPENDIX}

(see p. 259) 

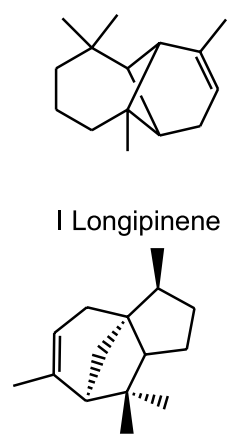

VI a-Cedrene<smiles>Cc1ccc2c(C)ccc(C(C)C)c2c1</smiles>

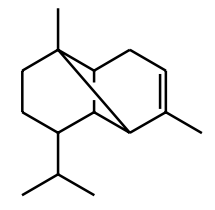

II Copaene<smiles>C=C1CCC(C(C)C)C2C=C(C)CCC12</smiles>

VII y-Cadinene

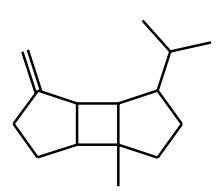

III Bourbonene

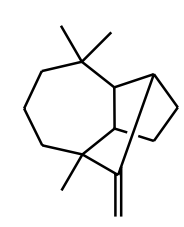

IV Longifolene<smiles>CC1=CC2C(CC1)C(C)=CCC2C(C)C</smiles><smiles>CCCC(C(C)C)C1CCCc2ccc(C)cc21</smiles><smiles>C=C1CC=C(C)CC2CC(C)(C)CC12</smiles>

V Caryophyllene<smiles>CC1=CC2C(=C(C)CCC2C(C)C)CC1</smiles>

X $\delta$-Cadinene<smiles>Cc1ccc2c(C)ccc(C(C)C)c2c1</smiles>

XI Cadina-1,3,5, ?-tetraene XII Cadina-1(10),6,8-triene XIII Cadina-1(10),?,6,8-teraene XIV Cadalene<smiles>C=C[C@H]1CCC2=C(CC[C@@H]3C(C)(C)CCC[C@@]23C)C1</smiles><smiles>C=C[C@]1(C)C=C2CC[C@H]3C(C)(C)CCC[C@]3(C)C2CC1</smiles><smiles>CC(C)c1ccc2c(c1)CC[C@@H]1[C@@H](C)CCC[C@@]21C</smiles><smiles>C=C[C@H]1CC[C@H]2C(=CC[C@@H]3C(C)(C)CCC[C@@]23C)C1</smiles>

XV Sandaracopimaradiene

XVI Isopimaradiene

XVII 19-Norabietatriene

XVIII Isopimara-7,15-diene<smiles>CC1=C2CCc3cc(C(C)C)ccc3[C@@]2(C)CCC1</smiles><smiles>C=C1CCC[C@]2(C)c3ccc(C(C)C)cc3CCC12</smiles><smiles>CC(C)c1ccc2c(c1)CC[C@@H]1[C@@H](C)CCC[C@@]21C</smiles>

XIX Norabieta-4,8,11,13-tetraene

XX Norabieta-4(19),8,11,13-tetraene

XXI 18-Norabietatriene<smiles>CC1=CCC[C@]2(C)c3ccc(C(C)C)cc3CCC12</smiles><smiles>CC(C)c1ccc2c(c1)CC=C1C(C)(C)CCC[C@]12C</smiles><smiles>CC(C)c1ccc2c(c1)CCC1C(C)(C)CCC[C@@]21C</smiles>

XXII Norabieta-3,8,11,13-tetraene

XXIII Abieta-?,8,11,13-tetraene

XXIV Dehydroabietane<smiles>CC(C)c1ccc2c3c(ccc2c1)C(C)(C)CCC3</smiles>

XXV Simonellite<smiles>C=C1CC23CCC4C(C)(C)CCCC4(C)C2CCC1C3</smiles>

XXIV Kaur-16-ene<smiles>Cc1cccc2c1ccc1cc(C(C)C)ccc12</smiles>

XXVII Retene

Appendix. Sesquiterpenoids and diterpenoids. 